\title{
A novel QCM immunosensor development based on gold nanoparticles functionalized sulfur-doped graphene quantum dot and h-ZnS-CdS NC for Interleukin-6 detection
}

\author{
Necip Atar ${ }^{\text {a }}$, Mehmet Lütfi Yola b, * \\ a Pamukkale University, Faculty of Engineering, Department of Chemical Engineering, Denizli, Turkey \\ ${ }^{\mathrm{b}}$ Hasan Kalyoncu University, Faculty of Health Sciences, Department of Nutrition and Dietetics, Gaziantep, Turkey
}

\section{H I G H L I G H T S}

- QCM based immunosensor is developed for Interleukin-6 detection.

- The prepared immunosensor is characterized by several methods.

- The prepared immunosensor shows high stability and selectivity.

- The prepared immunosensor is advantageous in comparison with the other analytical methods.

\section{A R T I C L E I N F O}

\section{Article history:}

Received 27 October 2020

Received in revised form

25 December 2020

Accepted 3 January 2021

Available online 7 January 2021

Keywords:

Antigen interleukin-6

QCM immunosensor

Sulfur-doped graphene quantum dot

h-ZnS-CdS NC
G R A P H I C A L A B S T R A C T

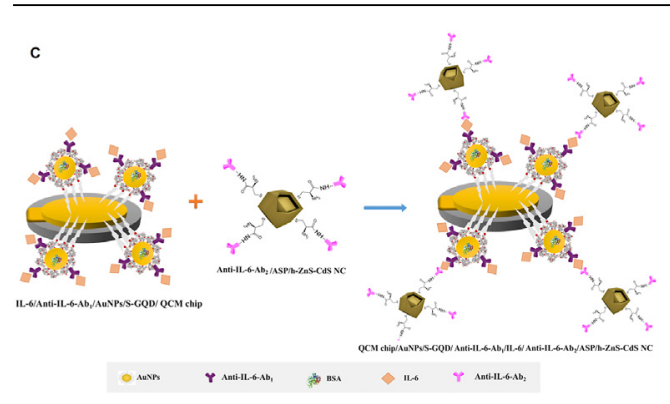




\section{Introduction}

One of significant biomarkers associated with chronic inflammation is inflammatory cytokines. Especially, the chronic inflammation can result in chronic diseases such as heart disease and arthritis [1]. IL-6 as inflammatory pluripotent cytokine is secreted by non-lymphoid cells and is an efficient biomarker for monitoring immune response in cancer progress [2]. The medical ailments such as acute stressors and cortisol secretion are directly related to IL-6 levels [3]. In addition, IL-6 has valuable role on metabolism responsible for glucose intake and insulin activity [4]. Moreover, its overexpression has been investigated in some tumor cells corresponding to microenvironment and immunomodulation [5]. When many scientists want to show the effects of high IL- 6 concentration, they can find the direct link between inflammation and cancer on the basis of IL-6 concentration [2]. IL-6's amount is $15.0-80.0 \mathrm{pg} \mathrm{mL}^{-1}$ in healthy people. Nonetheless, this ratio can increase until nanogram orders in diseases [6] and some significant diseases such as prostate [7] and breast cancer [8] start to emerge. Thus, IL-6 determination methods in plasma can be important monitoring system [9]. Up to now, the valuable analytical methods such as SERS-based flow biosensor, enzyme-linked immunosorbent and chemiluminescence were presented for protein biomarker analyzes [10,11]. Nonetheless, the long analysis time and costly instrumentation are needed on these methods [12]. Hence, more simple and easy analytical methods such as plasmonic biosensor microarrays [13] and surface plasmon resonance [11] were prepared and applied for IL-6 quantifications. Nonetheless, crucial disruptions occur due to low sensitivity towards analyte molecule. Currently, nano-structured materials have important attention in high sensor responses. In this regard, biosensors/immunosensors based on nanocomposites are important alternative to complexbulky devices.

Carbon-based nanomaterials such as graphene are currently utilized as support agent to increase Au NPs'sensor efficiency [14]. Graphene quantum dot as a member of 0-dimensional graphene family has considerable attention on sensor/biosensor technology owing to optoelectronic properties and high conductivity [15]. In addition, carbon as reducing agent may reduce $\mathrm{Au}^{3+}$ to $\mathrm{Au}$ NPs without surfactant, indicating environmentally friendly synthesis method.

CdS as excellent semiconductor material has about $2.4 \mathrm{eV}$ of narrow band gap. However, pure CdS can result in corrosive effect on many sensor applications [16,17]. Hence, materials' construction having heterojunction structure is an effective technique to eliminate this corrosive effect. The obtaining of better sensor performance can be provided by coupling materials with matching bandgaps. ZnS having $3.5 \mathrm{eV}$ of narrow band gap is widely utilized in solar cell and catalysis applications [18]. The prepared heterojunction structures with coupling $\mathrm{ZnS}$ with $\mathrm{CdS}$ can increase the binding affinities of the electrode materials as QCM or voltammetry [19].

Metal-organic frameworks (MOFs) as a class of functional materials can be prepared via the unification of organic ligands and metal ions. Due to MOFs' perfect crystallinity, biocompatibility and structural properties [20], they are currenty used in immunosensor technology [21-23]. Especially, MOFs with hollow structure have different advantages such as interior cavity and cavity volume. In addition, thin-shelled structures of hollow MOFs with a short charge transfer distance provide the easy complex formation with organic/inorganic agents [19].

Herein, a novel sandwich type QCM immunosensor based on gold nanoparticles functionalized sulfur-doped graphene quantum dot and hollow ZnS-CdS nanocage for IL-6 detection was developed. The results of analytical application demonstared that hollow
ZnS-CdS nanocage based QCM immunosensor had sensitive detection limit of $3.33 \mathrm{fg} \mathrm{mL} \mathrm{m}^{-1}$, perfect stability and selectivity. Thus, this study will provide a new opportunity for practical clinical application.

\section{Experimental}

\subsection{Materials}

Antigen IL-6, capture antibody1-IL-6 (anti-IL-6-Ab 1 ), detection antibody2-IL-6 (anti-IL-6-Ab 2 ), bovine serum albumin (BSA), vascular endothelial growth factor (VEGF), protein p53 (p53), interleukin-8 (IL-8), interleukin-1 $\beta$ (IL-1 $\beta$ ), $\mathrm{Zn}\left(\mathrm{NO}_{3}\right)_{2} \cdot 6 \mathrm{H}_{2} \mathrm{O}, 2$ methylimidazole (2-MI), 1-methylimidazole (1-MI), tannic acid (TA), thioacetamide (TAE), $\mathrm{CdCl}_{2} \cdot 2.5 \mathrm{H}_{2} \mathrm{O}$, citric acid (CA), 3mercaptopropionic acid (3-MPA), $\mathrm{HAuCl}_{4} \cdot 3 \mathrm{H}_{2} \mathrm{O}, 2$ 2-amino-3sulfhydrylpropanoic acid (ASP), $N$-(3-dimethylaminopropyl)- $N^{\prime}-$ ethylcarbodiimide (EDC), $\mathrm{N}$-hydroxysuccinimide (NHS) were obtained from Sigma-Aldrich. Phosphate buffer solution (PBS, $0.1 \mathrm{M}$, $\mathrm{pH}$ 7.0) was utilized as diluting and desortion agent.

\subsection{Instrumentation}

SEM and XRD images were obtained by using ZEISS EVO 50 SEM analytical microscopy and Rigaku X-ray diffractometer, respectively. XPS analysis was carried out by using PHI 5000 Versa Probe. TEM measurements were carried out by JEOL 2100 TEM. Gamry Reference 600 work-station (Gamry, USA) was utilized for CV and EIS measurements. FTIR measurements were obtained by Bruker Tensor 27 FT-IR with DTGS detector. QCM system (INFICON Acquires Maxtek) was used for analytical application of Interleukin-6.

\subsection{Synthesis of sulfur-doped graphene quantum dot (S-GQD), gold} nanoparticles functionalized S-GQD (AuNPs/S-GQD) nanocomposites as QCM sensor platform and QCM modification with AuNPs/S-GQD

CA (3.0 g) and 3-MPA ( $400.0 \mu \mathrm{L}, 4.0 \mathrm{mmol})$ was firstly subjected to pyrolysis treatment at $250^{\circ} \mathrm{C}$ for $1 \mathrm{~h}$ for S-GQD preparation. After cooling process, S-GQD was collected as bright yellow suspension. After that, the collected bright yellow $\boldsymbol{S}$-GQD was washed with deionized water and stored at $25^{\circ} \mathrm{C}$. The collected bright yellow SGQD was used as the reducing agent in process of AuNPs/S-GQD nanocomposite preparation. $\mathrm{HAuCl}_{4} \cdot 3 \mathrm{H}_{2} \mathrm{O}(200.0 \mu \mathrm{M})$ was firstly transferred into S-GQD solution $\left(0.25 \mathrm{mg} \mathrm{mL}^{-1}\right)$ for 20 min at $25^{\circ} \mathrm{C}$. The color transformation stage from yellow to pink indicated AuNPs/S-GQD nanocomposite formation. Finally, AuNPs/S-GQD nanocomposite was dried at $25^{\circ} \mathrm{C}$.

Firstly, gold surfaces of QCM chips were cleaned by acidic piranha solution $\left(3: 1 \mathrm{H}_{2} \mathrm{SO}_{4}: \mathrm{H}_{2} \mathrm{O}_{2}, \mathrm{v} / \mathrm{v}\right)$ on bath system for $30 \mathrm{~min}$. After that, the cleaned QCM chips were immersed into AuNPs/SGQD nanocomposite solution $\left(20.0 \mathrm{mg} \mathrm{mL}^{-1}\right)$ under strong stirring for $1 \mathrm{~h}$. Lastly, gold-sulfur affinity between QCM chip and AuNPs/S-GQD nanocomposite provided QCM chip modification (AuNPs/S-GQD/QCM).

\section{4. anti-IL-6-Ab ${ }_{1}$ and antigen IL-6 immobilization on QCM sensor platform}

After development of QCM sensor platforms with AuNPs/S-GQD nanocomposite, anti-IL-6-Ab $1\left(20.0 \mu \mathrm{L}, 10.0 \mu \mathrm{g} \mathrm{mL}^{-1}\right)$ was dropped on QCM sensor platforms at $37.0^{\circ} \mathrm{C}$ and QCM chips were maintained in closed box during $60 \mathrm{~min}$ for the successful immobilization via amino-gold affinity [24]. Hence, anti-IL-6-Ab $\mathbf{1} / \mathbf{A u N P s / S - ~}$ GQD/QCM chips were obtained and antigen IL-6 immobilization 

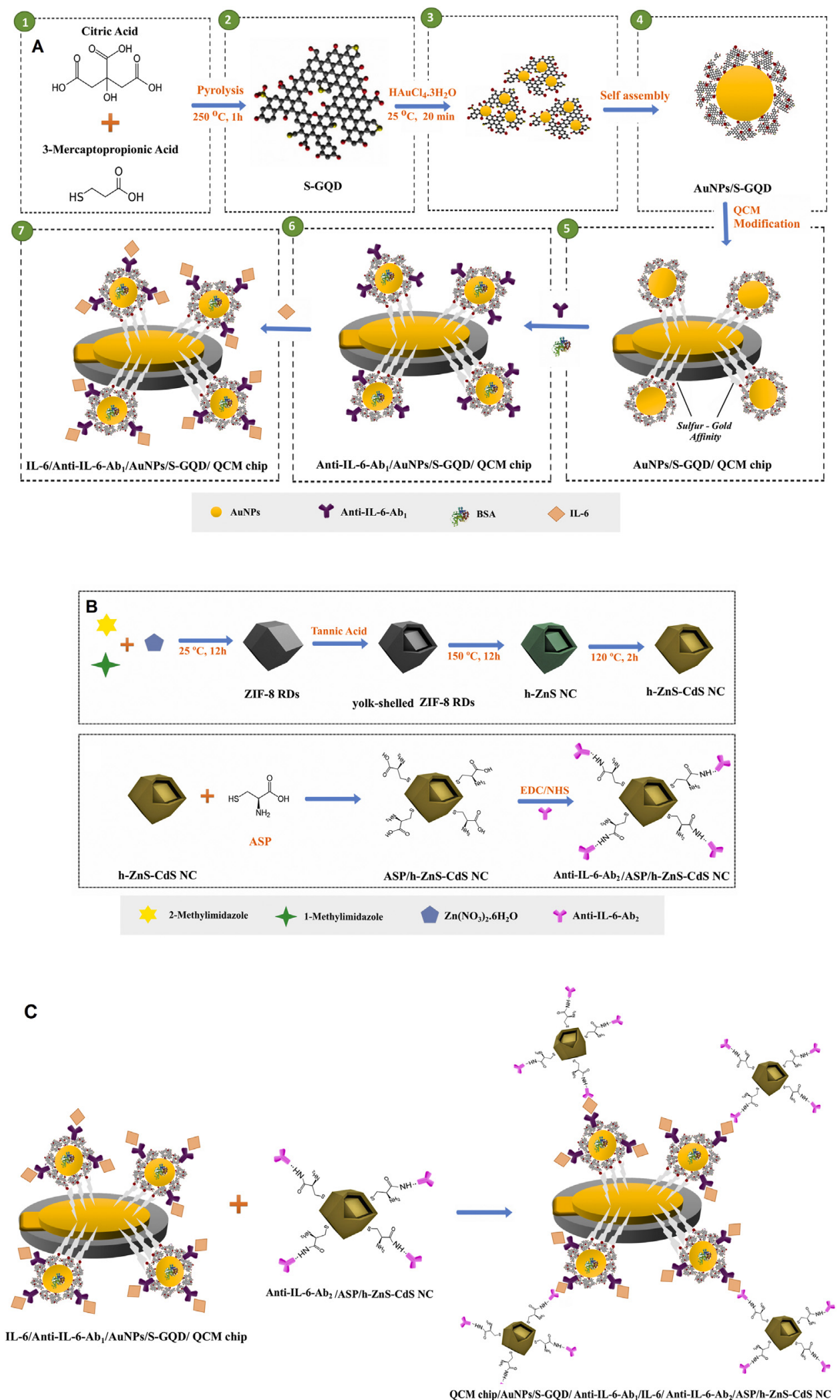
AuNPs
Y Anti-IL-6-Ab
$>$ IL-6 $\quad$ Anti-IL-6-Ab

Scheme. 1. Schematic presentation of (A) QCM sensor platform, (B) ASP-h-ZnS-CdS NC with anti-IL-6-Ab 2 conjugation and (C) developed QCM immunosensor. 
started on anti-IL-6-Ab $1 /$ AuNPs/S-GQD/QCM chips. Firstly, BSA blockage was provided on anti-IL-6-Ab 1 /AuNPs/S-GQD/QCM chips to eliminate non-specific interactions. This blockage treatment was performed by immersion of anti-IL-6-Ab 1 /AuNPs/S-GQD/QCM chip into BSA solution $(2.0 \% \mathrm{w} / \mathrm{v})$ at $37.0^{\circ} \mathrm{C}$ for $60 \mathrm{~min}$. Then, anti-IL-6$\mathrm{Ab}_{1} / \mathrm{AuNPs} / \mathrm{S}-\mathrm{GQD} / \mathrm{QCM}$ chips were incubated to immerse into antigen IL-6 solutions with different concentrations for $60 \mathrm{~min}$ at $37{ }^{\circ} \mathrm{C}$, providing IL-6/anti-IL-6-Ab//AuNPs/S-GQD/QCM chips. Chips were washed with 0.1 M PBS ( $\mathrm{pH} 7.0$ ) to remove unbounded IL-6 proteins. QCM chips were preserved without pressure fluctuations at $25{ }^{\circ} \mathrm{C}$ and QCM sensorgrams were also obtained in an enclosed cabinet to prevent from external environmental influences.

2.5. Synthesis of Zn-based zeolitic imidazolate rhombic dodecahedrons (ZIF-8 RDs), yolk-shelled ZIF-8 RDs, hollow ZnS nanocage ( $h$-ZnS NC), hollow ZnS-CdS nanocage ( $h-Z n S-C d S N C$ ), ASP incorporated $h-Z n S-C d S N C$ (ASP-h-ZnS-CdS NC) and ASP- $h$ ZnS-CdS NC with anti-IL-6-Ab 2 conjugation

After preparation of $\mathrm{Zn}\left(\mathrm{NO}_{3}\right)_{2} \cdot 6 \mathrm{H}_{2} \mathrm{O}$ solution in methanol $(100.0 \mathrm{~mL})$, the prepared solution was transferred into methanol solution containing 2-MI and 1-MI under strong stirring. After the incubation of the prepared solution at $25{ }^{\circ} \mathrm{C}$ for $12 \mathrm{~h}, \mathbf{Z I F - 8} \mathbf{R D s}$ (average size of about $2.33 \pm 0.07 \mu \mathrm{m}$ ) was obtained and dried at $70{ }^{\circ} \mathrm{C}$ [25]. After that, ZIF-8 RDs (100.0 mg) was transferred into methanol solution containing TA $(2.0 \mathrm{~g})$ under stirring treatment for $10 \mathrm{~min}$. After yolk-shelled ZIF-8 RDs was washed with methanol $(50.0 \mathrm{~mL})$, the product was collected via centrifugation at $10,000 \mathrm{rpm}$ [26]. After TAE (1.00 g) solution preparation in ethanol $(100.0 \mathrm{~mL})$, this solution was mixed with yolk-shelled ZIF-8 RDs $(100.0 \mathrm{mg})$. After strong stirring, the dispersion was transferred to a Teflon stainless steel at $150{ }^{\circ} \mathrm{C}$ for $12 \mathrm{~h}$. The obtained $\boldsymbol{h}$-ZnS NC was washed with methanol and dried at $25{ }^{\circ} \mathrm{C}$. Lastly, h-ZnS NC $\left(25.0 \mathrm{mg}\right.$ ) was transferred to $\mathrm{CdCl}_{2} \cdot 2.5 \mathrm{H}_{2} \mathrm{O}(2.00 \mathrm{mg})$ aqueous solution and the dispersion was maintained at $120{ }^{\circ} \mathrm{C}$ for $2 \mathrm{~h}$. After drying treatment, $\boldsymbol{h}-\mathbf{Z n S}$-CdS NC was obtained. After that, the obtained h-ZnS-CdS NC (10.0 mg) was mixed with $0.1 \mathrm{mM}$ ASP aqueous solution $(1.0 \mathrm{~mL})$ at $50{ }^{\circ} \mathrm{C}$ for 20 min under stirring treatment. $\boldsymbol{A S P}-\boldsymbol{h}-\mathbf{Z n S}$-CdS NC product was collected at 10,000 rpm for $30 \mathrm{~min}$ and dried under argon gas. Then, ASP-h-ZnS-CdS NC dispersion $\left(5.0 \mu \mathrm{L}, 5.0 \mathrm{mg} \mathrm{mL}^{-1}\right)$ was mixed with EDC/NHS solution $(10.0 \mu \mathrm{L}, 5.0 \mathrm{mM} / 1.0 \mathrm{mM})$ to activate $-\mathrm{COOH}$ groups of ASP-h-ZnSCdS NC. After the activation of $-\mathrm{COOH}$ groups, IL-6-Ab $2(20.0 \mu \mathrm{L}$, $10.0 \mu \mathrm{g} \mathrm{mL}^{-1}$ ) was incubated to ASP-h-ZnS-CdS NC via strong ester formation between - $\mathrm{COOH}$ of ASP-h-ZnS-CdS NC and $-\mathrm{NH}_{2}$ of IL-

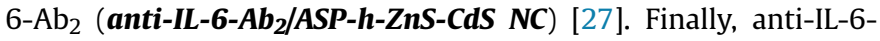
$\mathrm{Ab}_{2} / \mathrm{ASP}-\mathrm{h}-\mathrm{ZnS}-\mathrm{CdS} \mathrm{NC}$ was dispersed in 0.1 M PBS (pH 7.0) and stored at $4{ }^{\circ} \mathrm{C}$.

\subsection{QCM measurements}

A novel QCM immunosensor based on AuNPs/S-GQD/QCM chip and ASP-h-ZnS-CdS NC as signal amplification was prepared by antibody-antigen interaction. Firstly, each of IL-6/anti-IL-6-Ab 1 AuNPs/S-GQD/QCM chips was emplaced into the detection vessel. After washing with $0.1 \mathrm{M}$ PBS (pH 7.0), anti-IL-6-Ab $2 /$ ASP-h-ZnSCdS NC conjugation solution $\left(20.0 \mu \mathrm{L}, 15.0 \mathrm{mg} \mathrm{mL}^{-1}\right)$ was given into detection vessel and subjected to immune reaction with each of IL6/anti-IL-6-Ab 1 /AuNPs/S-GQD/QCM chips for $30 \mathrm{~min}$ (QCM/S-GQD/ AuNPs/anti-IL-6-Ab $/$ /IL-6/anti-IL-6-Ab $/$ /ASP-h-ZnS-CdS). The final substrates' frequencies were monitored in $0.1 \mathrm{M}$ PBS $(5.0 \mathrm{~mL}, \mathrm{pH}$ $7.0,1.0 \mathrm{~mL} \mathrm{~min}^{-1}$ of flow-rate) and the changes in the frequency were registered.

\subsection{Sample preparation}

IL-6 free plasma samples were supplied from Blood Bank in TURKEY. Sample preparation protocol was explained in detail on Supplementary Data [28].

\section{Results and discussion}

\subsection{Immunosensor principle for antigen IL-6 recognition}

In this report, sensitive voltammetric immunoassay method was developed for antigen IL-6 recognition by AuNPs/S-GQD/QCM as sensor platform and h-ZnS-CdS NC material as signal amplification. Firstly, AuNPs/S-GQD/QCM chip as sensor platform was efficiently prepared by gold-sulfur affinity in Section 2.3. The primary purpose of developed AuNPs/S-GQD/QCM chip was effective carrier for antiIL-6-Ab 1 via amino-gold affinity. In addition, graphene quantum dot was utilized as support agent for sensor performance enhancement of Au NPs [14] and prevention of Au NPs aggregation [29] (Scheme 1A).

Secondly, ZIF-8 RDs was prepared according to the literature [30]. After ZIF-8 RDs conversion into yolk-shelled ZIF-8 RDs by chemical etching, h-ZnS NC was obtained by sulfurization treatment with TAE. Eventually, hydrothermal cation-exchange treatment provided h-ZnS-CdS NC formation. Finally, ASP incorporated h-ZnS-CdS NC was prepared for anti-IL-6-Ab 2 conjugation (Scheme 1B). We can say that the highly stable QCM immunosensor was prepared in present report owing to strong ester bonds between - $\mathrm{COOH}$ of ASP incorporated h-ZnS-CdS NC and $-\mathrm{NH}_{2}$ of anti-IL-6$\mathrm{Ab}_{2}$. Semiconductor materials as $\mathrm{ZnS}$ show excellent chemical and physical properties [31]. Especially, heterojunction construction between $\mathrm{ZnS}$ and $\mathrm{CdS}$ can provide high efficiency for sensor applications [32]. Thus, selective and sensitive QCM immunosensor between AuNPs/S-GQD/QCM chip and ASP incorporated h-ZnS-CdS NC was developed for interleukin-6 analysis in this study (Scheme 1C).

\subsection{Characterization of S-GQD and AuNPS/S-GQD nanocomposite as QCM sensor platform}

Fig. 1A demonstrated the surface morphology of S-GQD, indicating homogeneous and well dispersion. Fig. 1 A showed the narrow sized distribution of S-GQD with average diameter of $4.2 \pm 0.7 \mathrm{~nm}$ [33]]. Fig. 1B indicated HRTEM image of S-GQD having the lattice spacing distance corresponded to (120) plane of graphene. According to Fig. 1C and 1D, S-GQD's height was obtained to be average $1.0 \mathrm{~nm}$. Fig. 1E demonstrated the successful AuNPs formation on TEM image of AuNPs/S-GQD nanocomposite and the mean diameter of nanocomposite was observed to be $16-18 \mathrm{~nm}$. Also, Fig. 1F showed two distinct fringes as outer and inner part, indicating the nanocomposite formation like core-shell type between AuNPs and S-GQD. This formation was corresponded to $\mathrm{Au}^{3+}$ attachment on S-GQD nanomaterial via specific Au-thiol linkage. Due to S-GQD nanomaterial as efficient reducing agent, the reduced species can turn into Au NPs to form core-shell type nanocomposite. Lastly, EDS analysis (Fig. 1G) of AuNPs/S-GQD nanocomposite showed the presence of $\mathrm{C}$, Au and $\mathrm{S}$ elements, clearly indicating the successful doping treatment of sulfur on graphene quantum dots and AuNPs formation on S-GQD.

The optical properties of S-GQD and AuNPs/S-GQD such as UV-visible spectroscopy were investigated (Fig. 2A). The absorption band at about $285 / \mathrm{nm}$ was observed for S-GQD, indicating successful sulfur doping on graphene quantum dots with graphitic's obvious absorption band [34]. However, the absorption band intensity at about $285 \mathrm{~nm}$ started to weaken during AuNPs 

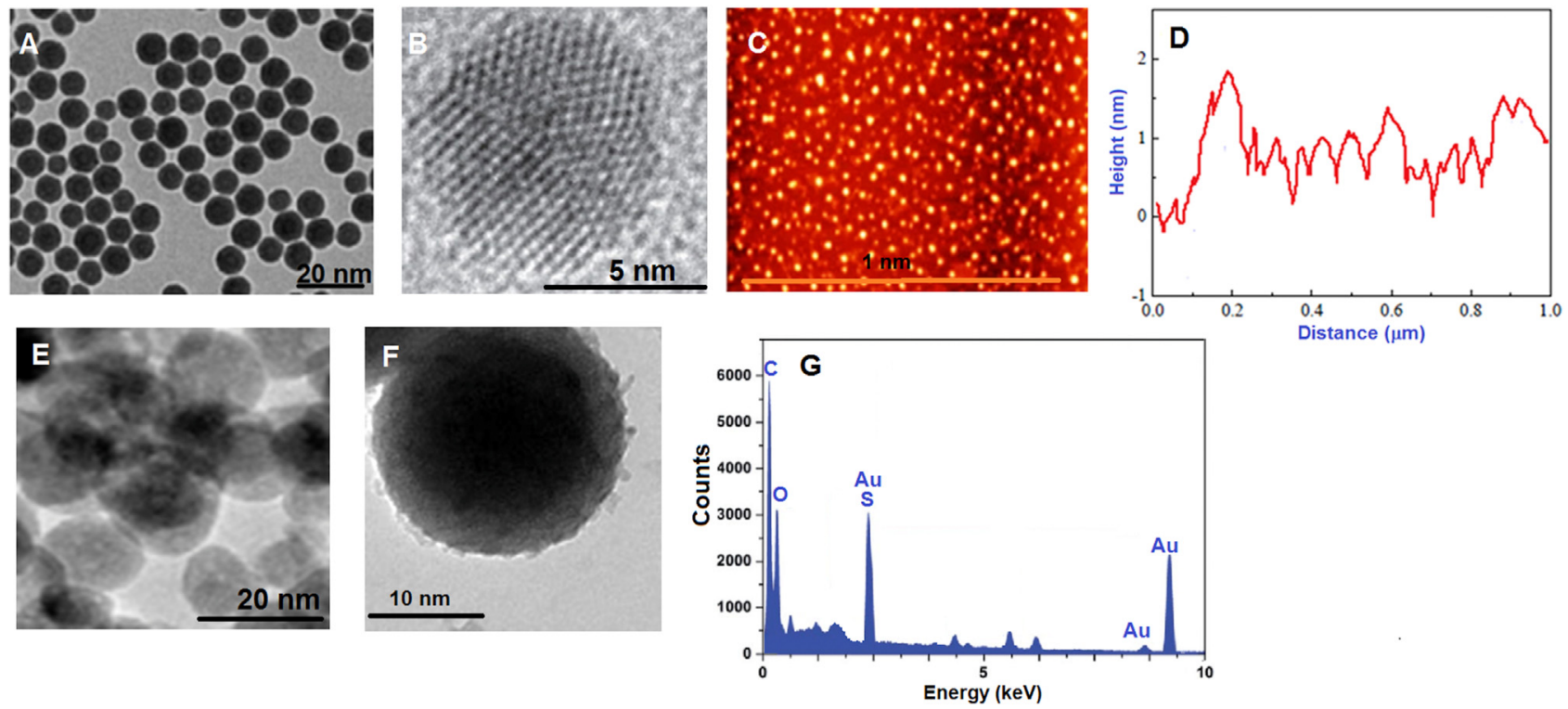

Fig. 1. (A) TEM, (B) HRTEM, (C) AFM images of S-GQD, (D) Topography of S-GQD obtained from AFM, (E) TEM image of AuNPs/S-GQD nanocomposite, (F) HRTEM image of AuNPs/SGQD nanocomposite, (G) EDS analysis of AuNPs/S-GQD nanocomposite.
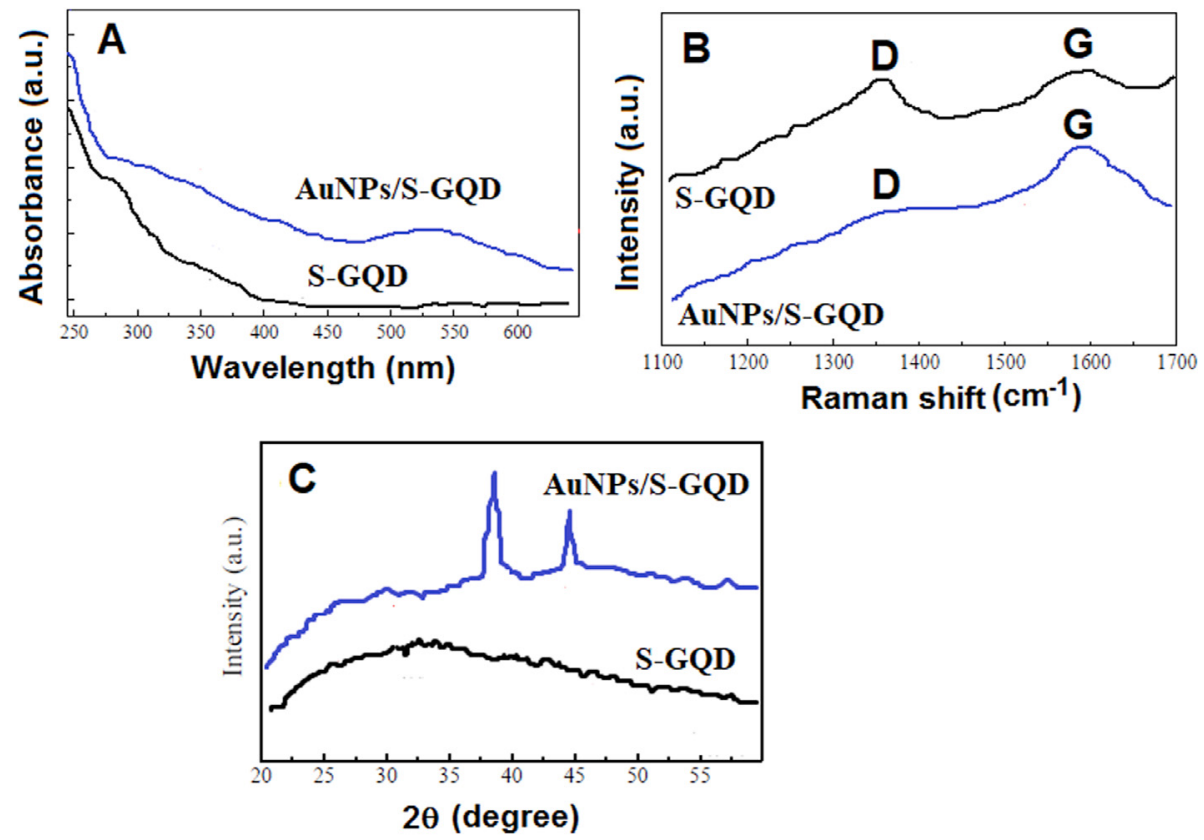

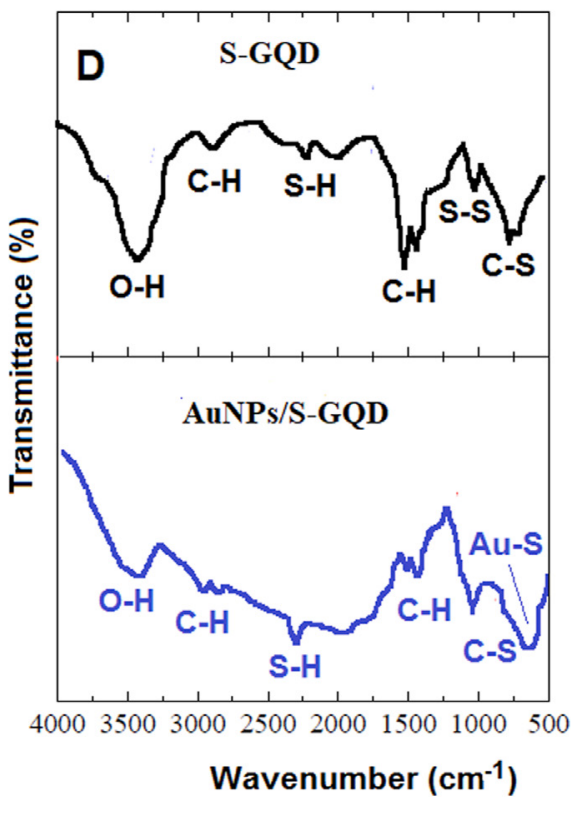

Fig. 2. (A) UV-visible spectra, (B) Raman spectra, (C) XRD patterns and (D) FTIR spectra of S-GQD and AuNPs/S-GQD nanocomposite.

formation on S-GQD, corresponding to reducing agent behavior of $\mathrm{S}-\mathrm{GQD}$ for $\mathrm{HAuCl}_{4} \cdot 3 \mathrm{H}_{2} \mathrm{O}$ solution. In addition, the absorption band of Au NPs at $520 \mathrm{~nm}$ was observed for nanocomposite [35], confirming the successful formation of Au NPs.

Raman spectroscopy was also utilized for the atomic structure's characterization of S-GQD and AuNPs/S-GQD nanocomposite (Fig. 2B). The peaks at 1350 and $1600 \mathrm{~cm}^{-1}$ on Raman spectrum of S-GQD were attributed to D and $G$ bands resulting from graphite and $\mathrm{C}-\mathrm{C}$ bond vibrations, respectively [36]. D band intensity clearly decreased on Raman spectrum of AuNPs/S-GQD nanocomposite, indicating defects' decrease on S-GQDs. In addition, the bands demonstrated blue-shifts such as 1342 for D band and $1591 \mathrm{~cm}^{-1}$ for $\mathrm{G}$ band. Lastly, $\mathrm{I}_{\mathrm{D}} / \mathrm{I}_{\mathrm{G}}$ ratio value decreased from 0.94 to 0.83 .
Hence, these results indicated that the preparations of S-GQDs and AuNPs/S-GQD nanocomposite were performed in this study.

According to XRD patterns (Fig. 2C), the peak at $2 \theta=28.5^{\circ}$ corresponding to (002) plane of graphite confirmed S-GQDs presence [37]. After AuNPs/S-GQD nanocomposite preparation, the peaks at $2 \theta=38.1^{\circ}$ and $44.7^{\circ}$ attributing to (111) and (200) planes showed that AuNPs formation on sulfur-doped graphene quantum dot was accomplished. Finally, FTIR spectra of S-GQD and AuNPs/SGQD nanocomposite were obtained (Fig. 2D). The intensitive peak at $3489 \mathrm{~cm}^{-1}$ corresponding to stretching vibration of $\mathrm{O}-\mathrm{H}$ confirmed S-GQD's hydrophilic feature. The peaks at 2931 and $2292 \mathrm{~cm}^{-1}$ were attributed to the stretching vibrations of $\mathrm{C}-\mathrm{H}$ in graphitic structure and $\mathrm{S}-\mathrm{H}$ bond on $\mathrm{S}-\mathrm{GQD}$ spectrum. Also, 
absorption bands at 1569 and $1479 \mathrm{~cm}^{-1}$ were corresponded to bending vibration of $\mathrm{C}=\mathrm{C}$ bond of graphene. Finally, the absorption bands at $1053 \mathrm{~cm}^{-1}$ and $802 \mathrm{~cm}^{-1}$ corresponding to $S-S$ bond and $\mathrm{C}-\mathrm{S}$ stretching indicated successful sulfur doping treatment on graphene quantum dot. For AuNPs/S-GQD nanocomposite, the peak at 719 and was attributed to $\mathrm{Au}-\mathrm{S}$ [38,39], indicating nanocomposite formation between AuNPs and S-GQD.

\subsection{Characterization of ZIF-8 RDs, yolk-shelled ZIF-8 RDs, $h$-ZnS NC and $h$-ZnS-CdS NC}

The obvious XRD peaks belonging to (002), (112), (022), (013) and (222) planes demonstrates the successful synthesis of ZIF-8 RDs [40,41]. Also, XRD pattern of yolk-shelled ZIF-8 RDs is similar to that of ZIF-8 RDs and it is concluded that the applied chemical etching treatment can not damage the crystal structure (Fig. 3A). The typical rhombic dodecahedral structure on Fig. 3B confirmed the successful formation of ZIF-8 RDs. In the same way, the rhombic dodecahedral morphology was protected during chemical etching (Fig. 3C) for yolk-shelled ZIF-8 RDs. TEM image of ZIF-8 RDs (Fig. 3D) showed normal structure of rhombic dodecahedral morphology. Finally, the existing space between the interior cores and the outer shells (Fig. 3E) indicated that the etching treatment occurred to form yolk-shelled ZIF-8 RDs [41,42]. Fig. 4A and Fig. 4B indicated that after various chemical treatments, rhombic dodecahedron morphology of h-ZnS NC and h-ZnS-CdS NC structures was protected. In addition, the obvious rhombic structure of h-ZnSCdS NC was observed on Fig. 4C, indicating the verification of hZnS-CdS NC structure's SEM image. Finally, EDS analysis (Fig. 4D) showed that the presence of $\mathrm{Zn}, \mathrm{Cd}$ and S elements confirmed the successful formation of h-ZnS-CdS NC material. FTIR spectra of ASP, $\mathrm{h}-\mathrm{ZnS}-\mathrm{CdS}$ NC and ASP-h-ZnS-CdS NC were given on Fig. 4E.
Absorption bands at $3352 \mathrm{~cm}^{-1}, 3022 \mathrm{~cm}^{-1}, 2568 \mathrm{~cm}^{-1}, 1589 \mathrm{~cm}^{-1}$, $1412 \mathrm{~cm}^{-1}$ and $1151 \mathrm{~cm}^{-1}$, corresponding to $\mathrm{O}-\mathrm{H}, \mathrm{C}-\mathrm{H}, \mathrm{S}-\mathrm{H}, \mathrm{C}-\mathrm{C}$, $\mathrm{H}-\mathrm{C}-\mathrm{H}$ and $\mathrm{C}-\mathrm{O}$, respectively, were shown for ASP. Extra different absorption bands at $614 \mathrm{~cm}^{-1}$ and $579 \mathrm{~cm}^{-1}$, attributing to $\mathrm{Cd}-\mathrm{S}$ and $\mathrm{Cd}-\mathrm{S}-\mathrm{Zn}$ bending, were observed on FTIR spectrum of h$\mathrm{ZnS}-\mathrm{CdS} \mathrm{NC}$ and the absorption band at $2568 \mathrm{~cm}^{-1}$ relating to $\mathrm{S}-\mathrm{H}$ disappeared. S-H band disappearance confirmed disulphide (S-S) bond formation between ASP and h-ZnS-CdS NC [43].

Fig. S1A showed the certain XRD peaks belonging to (111), (220) and (311) and these peaks are in harmony with literature for h-ZnS $\mathrm{NC}$ [44]. In the same way, the certain XRD peaks belonging to (100), (002), (101), (102), (110), (103) and (112) are consistent to literature for h-ZnS-CdS NC material [45]. Thus, h-ZnS-CdS NC material consists of $\mathrm{ZnS}$ and CdS. In addition, the presence of h-ZnS-CdS NC material was confirmed by XPS. Zn, Cd ana S peaks were observed on XPS survey spectra (Fig. S1B) and these XPS survey peaks demonstrated that the results of XPS and EDS were in harmony. The binding energies at $1048.1 \mathrm{eV}$ for $\mathrm{Zn} 2 \mathrm{p}^{3 / 2}$ and $1026.7 \mathrm{eV}$ for $\mathrm{Zn} 2 \mathrm{p}^{1 / 2}$ on high-resolution spectrum of $\mathrm{Zn}$ indicated the valence state of $\mathrm{Zn}^{2+}$ (Fig. S1C) [46,47]. The binding energies at $406.1 \mathrm{eV}$ and $413.8 \mathrm{eV}$, corresponding to $\mathrm{Cd} 3 \mathrm{~d}^{5 / 2}$ and $\mathrm{Cd} 3 \mathrm{~d}^{3 / 2}$, showed the cadmium presence on h-ZnS-CdS NC material (Fig. S1D) $[47,48]$. Lastly, XPS peaks at $163.3 \mathrm{eV}$ and $162.2 \mathrm{eV}$ were attributed to S2p $\mathrm{p}^{1 / 2}$ and $\mathrm{S} 2 \mathrm{p}^{3 / 2}$ specific peaks, respectively (Fig. S1E) [49]. Optical properties of h-ZnS NC and h-ZnS-CdS NC were highlighted by UV-visible spectroscopy (Fig. S1F). The absorption band of h-ZnSCdS NC material shifted to more positive (about $500 \mathrm{~nm}$ ) in comparison with h-ZnS NC (about $350 \mathrm{~nm}$ ). This positive absorbance shift was corresponded to CdS incorporation into h-ZnS NC [26].
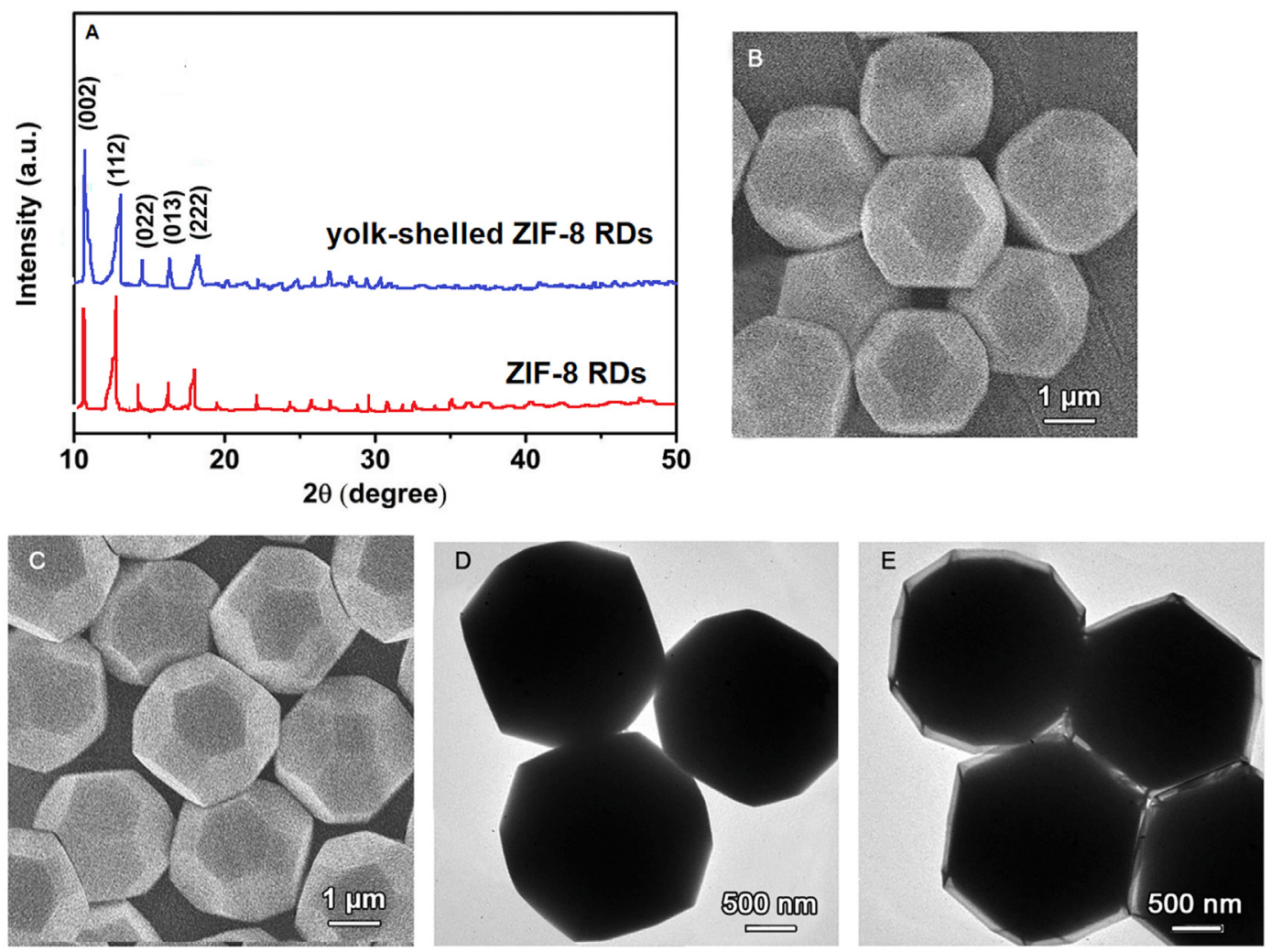

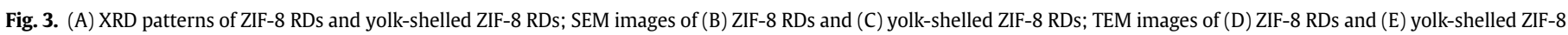
RDs. 

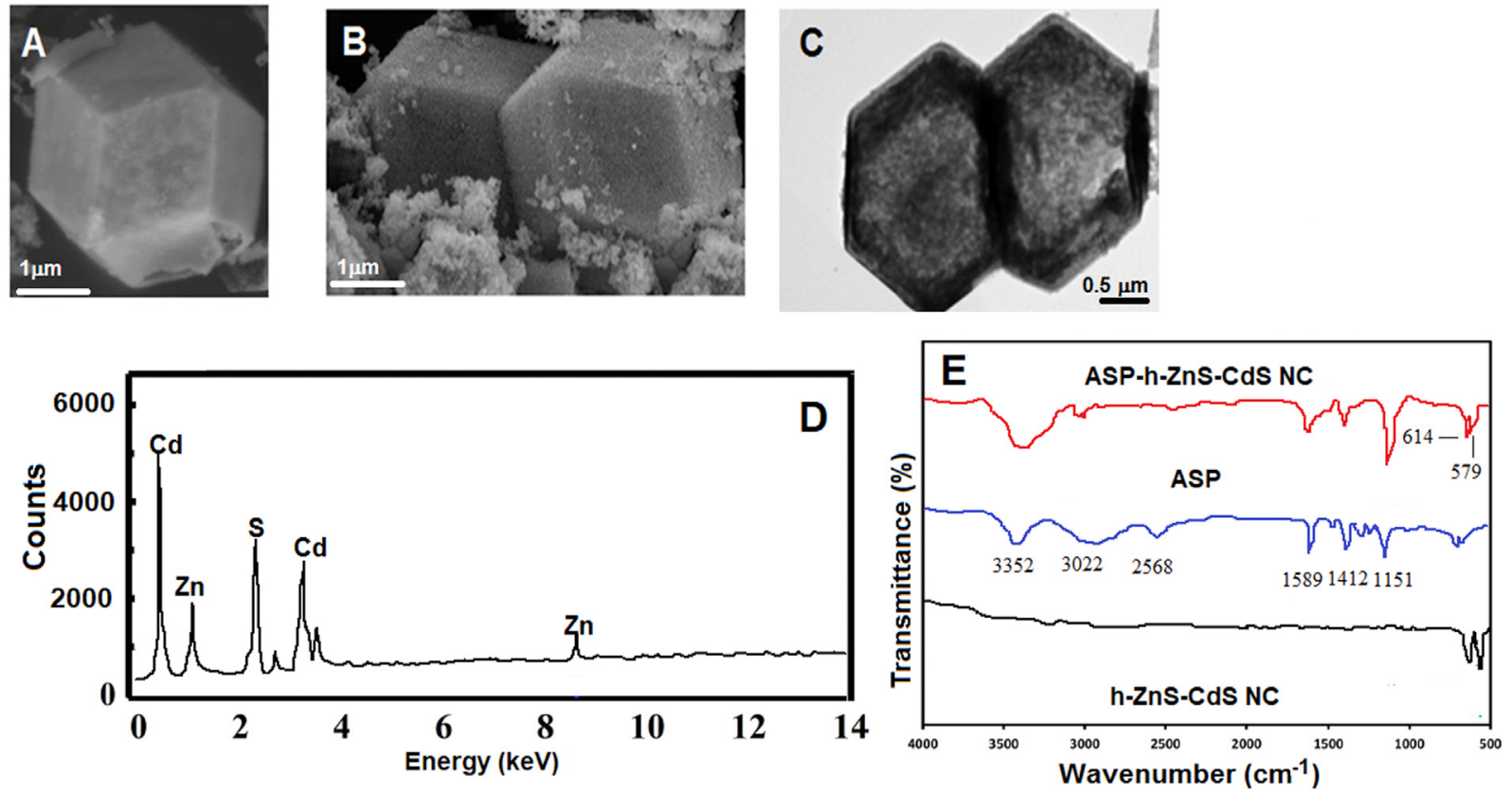

Fig. 4. SEM images (A) h-ZnS NC, (B) h-ZnS-CdS NC, TEM image of (C) h-ZnS-CdS NC, (D) EDS analysis of h-ZnS-CdS NC and (E) FTIR spectra of ASP, h-ZnS-CdS NC and ASP-h-ZnSCdS NC.
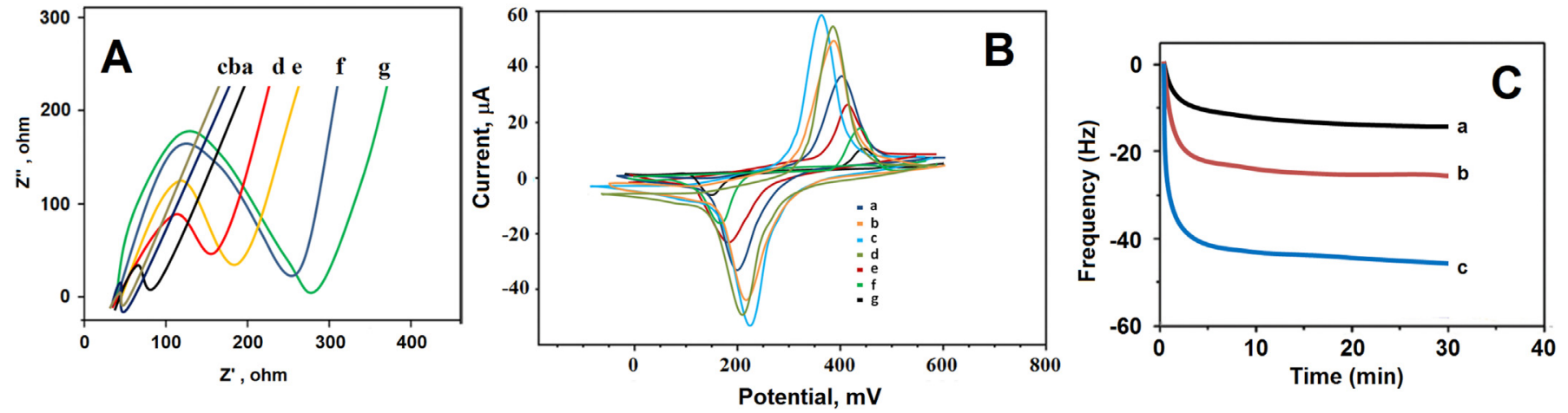

Fig. 5. (A) EIS and (B) CV at (a) bare GCE, (b) AuNPs/GCE, (c) AuNPs/S-GQD/GCE, (d) anti-IL-6-Ab $1 /$ AuNPs/S-GQD/GCE, (e) BSA/anti-IL-6-Ab/AuNPs/S-GQD/GCE, (f) IL-6/BSA/anti-IL6-Ab $1 /$ AuNPs/S-GQD/GCE, (g) NC CdS-ZnS-h-ASP/anti-IL-6-Ab $/$ /L-6/BSA/anti-IL-6-Ab $1 /$ AuNPs/S-GQD/GCE in $1.0 \times 10^{-3} \mathrm{M} \mathrm{K}_{3} \mathrm{Fe}(\mathrm{CN})_{6}$ including $0.1 \mathrm{M}$ KCl and (C) QCM responses (frequency vs. time) of (a) anti-IL-6-Ab $1 /$ AuNPs/S-GQD/QCM, (b) IL-6/anti-IL-6-Ab $1 /$ AuNPs/S-GQD/QCM, (c) anti-IL-6-Ab $/$ /ASP-h-ZnS-CdS NC conjugated to IL-6/anti-IL-6-Ab 1 / AuNPs/S-GQD/QCM (Final immunosensor including $1.0 \mathrm{pg} \mathrm{mL}^{-1} \mathrm{IL}-6$ ).

\subsection{Immunosensor's electrochemical and QCM characterizations}

Firstly, EIS method was utilized for immunosensor's characterization in $1.0 \times 10^{-3} \mathrm{M} \mathrm{K} \mathrm{K}_{3} \mathrm{Fe}(\mathrm{CN})_{6}$ including $0.1 \mathrm{M} \mathrm{KCl}$ solution (Fig. 5A). The small capacitive resistance was observed at bare GCE (curve a). When S-GQD/GCE (curve b) and AuNPs/S-GQD/GCE (curve c) were used, due to electron transfer's facilitation and high conductivity on electrode surface [50,51]. They caused a decrease in capacitive resistance in comparison with bare GCE. When anti-IL-6-Ab ${ }_{1}$, BSA, antigen IL-6 and anti-IL-6-Ab $/$ /ASP-hZnS-CdS NC were gradually conjugated to AuNPs/S-GQD/GCE (curve d-g), electron transfer was gradually appeared to be more difficult owing to inhibition effects of antibody-antigen interaction on electrode surface. Thus, it is concluded that efficient immobilization and conjugation of antibody-antigen on electrode surface are successfully performed.

Secondly, CV method was applied to the developed electrodes for investigation of antibody-antigen interactions in
$1.0 \times 10^{-3} \mathrm{M} \mathrm{K}_{3} \mathrm{Fe}(\mathrm{CN})_{6}$ including $0.1 \mathrm{M} \mathrm{KCl}$ solution at $100 \mathrm{mV} \mathrm{s}^{-1}$ (Fig. 5B). Curve a demonstrated that bare GCE had electrochemical anodic and cathodic signals for $\mathrm{K}_{3} \mathrm{Fe}(\mathrm{CN})_{6}$. Due to optical and physicochemical properties of AuNPs [52] and large surface area, quantum confinement and edge effects of graphene quantum dots [53], the more obvious current signals were observed (curve b and

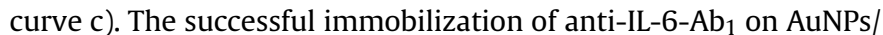
S-GQD/GCE was confirmed by obvious decreases in current signals (curve d). In addition, the blockage effect of BSA provided further decreases in current signals (curve e). Lastly, IL-6/BSA/anti-IL-6$\mathrm{Ab}_{1} /$ AuNPs/S-GQD/GCE (curve f) and ASP-h-ZnS-CdS NC based immunosensor (curve $\mathrm{g}$ ) showed the important decreases in electrochemical catalytic effect due to specific interactions between antigen IL-6 and anti-IL-6-Ab 2 . Hence, the successful immunosensor preparation was provided for antigen IL- 6 detection in this study. Finally, QCM characterizations were gradually provided for developed immunosensor. Sensorgram a showed the initial baseline at anti-IL-6-Ab $1 /$ AuNPs/S-GQD/QCM. The immunoreaction was 
seen with QCM frequency increase on Sensorgram b, indicating antigen IL-6 immobilization with anti-IL- $6-\mathrm{Ab}_{1}$ on QCM gold surface. After that, the more frequency shifts were observed by specific antibody-antigen interactions between IL-6/anti-IL-6-Ab 1 /AuNPs/ S-GQD and anti-IL-6-Ab 2 /ASP-h-ZnS-CdS NC. According to Fig. 5C, the proven interaction by $\mathrm{CV}$ and EIS experiments was again confirmed via QCM method.

\subsection{Optimization studies for QCM applications}

The effects of $\mathrm{pH}$, anti-IL-6-Ab $/$ /ASP-h-ZnS-CdS NC solution concentration and immune reaction time between anti-IL-6- $\mathrm{Ab}_{2} /$ ASP-h-ZnS-CdS NC and IL-6/anti-IL-6-Ab $1 /$ AuNPs/S-GQD/QCM chips were evaluated on Fig. S2.

\subsection{Linearity range}

The found linearity (Fig. 6) between QCM immunosensor and IL6 concentration was y $(\mathrm{Hz})=50.029 \times\left(\mathrm{pg} \mathrm{mL}^{-1}\right)-0.1701$ (inset of Fig. 6). The values as $0.01 \mathrm{pg} \mathrm{mL}^{-1}$ and $3.33 \mathrm{fg} \mathrm{mL}^{-1}$ were calculated for quantification limit (LOQ) and detection limit (LOD), respectively, by equations ( 1 ) and (2):

$\mathrm{LOQ}=10.0 \mathrm{~S} / \mathrm{m}$

$\mathrm{LOD}=3.3 \mathrm{~S} / \mathrm{m}$

Where $S$ is standard deviation of intercept and $m$ is slope of calibration equation. Some collation parameters between QCM immunosensor and some analytical methods for IL-6 detection were demonstrated on Table 1. Firstly, it is concluded that more simple, fast, selective and sensitive QCM based immunosensor was presented via this study in comparison with other analysis methods. Especially, stable QCM signals were observed by strong ester bonds between - $\mathrm{COOH}$ of ASP incorporated h-ZnS-CdS NC and $-\mathrm{NH}_{2}$ of anti-IL-6- $\mathrm{Ab}_{2}$. In addition, this esterification reaction can not require a crosslinker, indicating an environmentally friendly immunosensor. The synthesis procedure including AuNPs/ S-GQD and ASP-h-ZnS-CdS NC nanomaterials was low-cost and easy. Moreover, QCM based immunosensor can analyze antigen IL6 in shorter time than ELISA. The used analytical methods such as surface-enhanced raman spectroscopy for IL-6 detection are highcost and complicated in comparison with QCM immunosensor. Thus, some important clinical applications can be successfully performed by the developed QCM immunosensor.

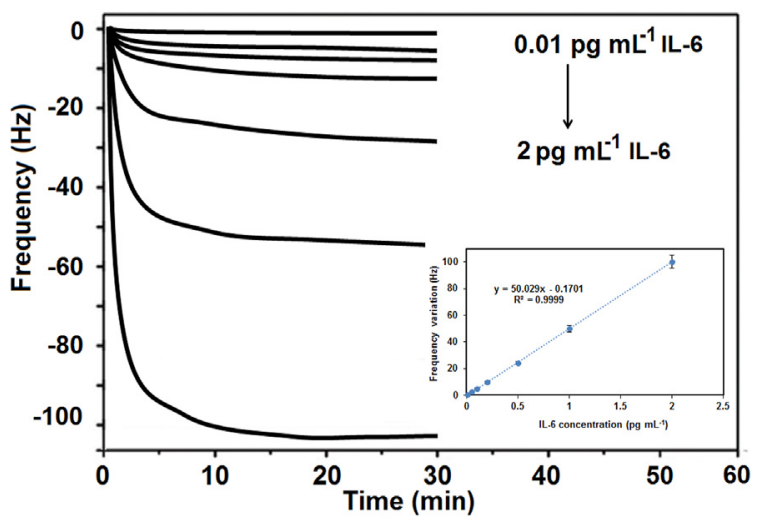

Fig. 6. Concentration effect (from 0.01 to $2.0 \mathrm{pg} \mathrm{mL}^{-1}$ IL-6) on QCM frequency, Inset: Calibration curve for QCM immunosensor.

\subsection{Recovery}

Initially, recovery tests (Table S1) were carried out to show the selectivity of QCM based immunosensor in prepared plasma samples. Recovery values were calculated as ratio between the found value and the real value. Close values to $100.00 \%$ indicated that QCM based immunosensor can detect antigen IL-6 with high selectivity in the presence of interference protein biomarkers such as BSA, VEGF, p53, IL-8 and IL-1 $\beta$. Furthermore, standard addition technique was utilized to demonstrate the effects of interference protein biomarkers and the calibration curve of $y$ $(\mathrm{Hz})=50.183 \times\left(\mathrm{pg} \mathrm{mL}^{-1}\right)+1.2379$ was obtained. According to the obtained slopes in direct calibration and standard addition techniques, QCM based immunosensor having high selectivity was successfully prepared for IL-6 detection.

\subsection{Selectivity}

To show the another selectivity test of QCM based immunosensor, QCM based immunosensor was utilized for other biomarkers (Fig. S3A). The comparison with the frequency shift for target IL- 6 and interference protein biomarkers with high concentration indicated that the frequency shifts of QCM based immunosensor were small for BSA, VEGF, p53, IL-8 and IL-1 $\beta$. Thus, QCM based immunosensor responses had satisfactory selectivity for antigen IL-6 (Fig. S3B).

\subsection{Reproducibility, stability and reusability}

The immunosensors based on antigen-antibody interaction with non-covalent binding such as electrostatic and hydrogen bonding can be affected by obvious conditions (acidic/alkaline solution or sonication). Especially, the immunoreagents can be exposed to functional damages. In this regard, 30 QCM based immunosensors including $1.0 \mathrm{pg} \mathrm{mL}^{-1}$ IL-6 were prepared for reproducibility test. The RSD value of obtained 30 frequency shifts could be calculated as $1.28 \%$, indicating the reliability of the immunosensor production procedure.

Moreover, the storage stability of QCM based immunosensor was investigated during 8 weeks. The whole QCM based immunosensors including $1.0 \mathrm{pg} \mathrm{mL}^{-1} \mathrm{IL}-6$ were stored at $4{ }^{\circ} \mathrm{C}$. According to Fig. S3C, frequency shifts were about $98.3 \%$ of original value during 8 weeks, confirming long-time storage stability.

Lastly, the reusability of QCM based immunosensor including $1.0 \mathrm{pg} \mathrm{mL}^{-1}$ IL- 6 was investigated. The RSD value of obtained frequency shifts was $1.36 \%$ for at least 40 usage of one QCM based immunosensor. Thus, the prepared QCM based immunosensor had a high degree of reusability.

\section{Conclusions}

In conclusion, a novel QCM immunosensor based on AuNPs/SGQD and ASP-h-ZnS-CdS NC nanomaterial for Interleukin-6 detection was developed and applied to IL-6 free plasma samples with high selectivity. This QCM immunosensor consisted of the sandwich-type immunoreactions. QCM immunosensor's highlights are as follows: (i) highly stable QCM immunosensor was prepared due to strong ester bonds. (ii) environmentally friendly immunosensor without a crosslinker was presented. (iii) the analysis of Interleukin-6 was performed in short time comparison with conventional methods such as ELISA. A linearity of $0.01-2.0 \mathrm{pg} \mathrm{mL}^{-1}$ was obtained with detection limit of $3.33 \mathrm{fg} \mathrm{mL}^{-1}$ by this novel QCM immunosensor. Hence, the developed QCM immunosensor can be used as alternative method for clinical diagnosis. 
Table 1

Comparison of QCM immunosensor with other methods for antigen IL-6 detection.

\begin{tabular}{|c|c|c|c|}
\hline Biosensor/Method & Linear Range & LOD & Ref. \\
\hline Impedimetric & $5.00-100.0 \mathrm{pg} \mathrm{mL}^{-1}$ & $1.60 \mathrm{pg} \mathrm{mL}^{-1}$ & [54] \\
\hline Impedimetric & $1.0 \mathrm{pg} \mathrm{mL}^{-1}-15.0 \mu \mathrm{g} \mathrm{mL}^{-1}$ & $0.33 \mathrm{pg} \mathrm{mL}^{-1}$ & [55] \\
\hline DPV & $0.0-100.0 \mathrm{pg} \mathrm{mL}^{-1}$ & $1.0 \mathrm{pg} \mathrm{mL}^{-1}$ & [56] \\
\hline AgNP-TiP & $0.0005-10.0 \mathrm{ng} \mathrm{mL}^{-1}$ & $0.1 \mathrm{pg} \mathrm{mL}^{-1}$ & [57] \\
\hline SERS & $1.0 \mathrm{pg} \mathrm{mL}^{-1}-1.0 \mu \mathrm{g} \mathrm{mL}^{-1}$ & $1.0 \mathrm{pg} \mathrm{mL}^{-1}$ & [58] \\
\hline LFIA & $2.0-500.0 \mathrm{pg} \mathrm{mL}^{-1}$ & $0.37 \mathrm{pg} \mathrm{mL}^{-1}$ & [59] \\
\hline Aptamer-coated AuNPs & $3.3-125.0 \mu \mathrm{g} \mathrm{mL}^{-1}$ & $1.95 \mu \mathrm{g} \mathrm{mL}^{-1}$ & [60] \\
\hline GO thin film & $1.0-300.0 \mathrm{pg} \mathrm{mL}^{-1}$ & $1.0 \mathrm{pg} \mathrm{mL}^{-1}$ & [61] \\
\hline SERS-ICA & $10.0-100.0 \mathrm{pg} \mathrm{mL}^{-1}$ & $7.897 \mathrm{pg} \mathrm{mL}^{-1}$ & [62] \\
\hline LFIA & $2.0-500.0 \mathrm{pg} \mathrm{mL}^{-1}$ & $0.37 \mathrm{pg} \mathrm{mL}^{-1}$ & [59] \\
\hline Impedimetric & $0.02-16.0 \mathrm{pg} \mathrm{mL}^{-1}$ & $6.00 \mathrm{fg} \mathrm{mL}^{-1}$ & [63] \\
\hline ELISA/Colorimetric & $10.24-400.0 \mathrm{pg} \mathrm{mL}^{-1}$ & $1.00 \mathrm{pg} \mathrm{mL}^{-1}$ & [64] \\
\hline ELISA/Colorimetric & $3.0-1000.0 \mathrm{pg} \mathrm{mL}^{-1}$ & $3.00 \mathrm{pg} \mathrm{mL}^{-1}$ & [65] \\
\hline QCM immunosensor & $0.01-2.0 \mathrm{pg} \mathrm{mL^{-1 }}$ & $3.33 \mathrm{fg} \mathrm{mL}^{-1}$ & This study \\
\hline
\end{tabular}

AgNP-TiP: Silver nanoparticle-hollow titanium phosphate sphere; SERS: Surface-enhanced Raman scattering; LFIA: lateral flow immunoassay; AuNPs: Gold nanoparticles; GO: Graphene oxide; SERS-ICA: surface enhanced Raman scattering immunochromatographic assay; LFIA: lateral flow immunoassay.

\section{CRediT authorship contribution statement}

Necip Atar: fabricated an ultra-sensitive sandwich type QCM immunosensor, Supervision. Mehmet Lütfi Yola: Writing - original draft, conceived the original idea and wrote the manuscript. fabricated an ultra-sensitive sandwich type QCM immunosensor.

\section{Declaration of competing interest}

The authors declare that they have no known competing financial interests or personal relationships that could have appeared to influence the work reported in this paper. The paper is original and is not published previously in whole or a part and not being considered elsewhere.

\section{Acknowledgement}

Mehmet Lütfi YOLA would like to thank Turkish Academy of Sciences (TUBA- GEBIP) for their invaluable invaluable support.

\section{Appendix A. Supplementary data}

Supplementary data to this article can be found online at https://doi.org/10.1016/j.aca.2021.338202.

\section{References}

[1] M.D. Hladek, S.L. Szanton, Y.-E. Cho, C. Lai, C. Sacko, L. Roberts, J. Gill, Using sweat to measure cytokines in older adults compared to younger adults: a pilot study, J. Immunol. Methods 454 (2018) 1-5.

[2] N. Kumari, B.S. Dwarakanath, A. Das, A.N. Bhatt, Role of interleukin-6 in cancer progression and therapeutic resistance, Tumor Biol. 37 (2016) 11553-11572.

[3] A.N. Vgontzas, M. Zoumakis, E.O. Bixler, H.-M. Lin, P. Prolo, A. Vela-Bueno, A. Kales, G.P. Chrousos, Impaired nighttime sleep in healthy old versus young adults is associated with elevated plasma interleukin-6 and cortisol levels: physiologic and therapeutic implications, J. Clin. Endocrinol. Metab. 88 (2003) 2087-2095.

[4] F.T. Wunderlich, P. Ströhle, A.C. Könner, S. Gruber, S. Tovar, H.S. Brönneke, L. Juntti-Berggren, L.-S. Li, N. van Rooijen, C. Libert, P.-O. Berggren, J.C. Brüning, Interleukin-6 signaling in liver-parenchymal cells suppresses hepatic inflammation and improves systemic insulin action, Cell Metabol. 12 (2010) 237-249.

[5] M. Catalfamo, C. Le Saout, H.C. Lane, The role of cytokines in the pathogenesis and treatment of HIV infection, Cytokine Growth Factor Rev. 23 (2012) 207-214.

[6] K.-Z. Liang, J.-S. Qi, W.-J. Mu, Z.-X. Liu, Conductometric immunoassay for interleukin-6 in human serum based on organic/inorganic hybrid membranefunctionalized interface, Bioproc. Biosyst. Eng. 32 (2009) 353-359.

[7] L.R. W Mattox, B.S. Baker, Autoregulation and multifunctionality among transacting factors that regulate alternative pre-mRNA processing, J. Biol. Chem. 267 (1992) 19698-19704.

[8] J. Domingo-Domenech, C. Oliva, A. Rovira, J. Codony-Servat, M. Bosch,
X. Filella, C. Montagut, M. Tapia, C. Campás, L. Dang, M. Rolfe, J.S. Ross, P. Gascon, J. Albanell, B. Mellado, Interleukin 6, a nuclear factor- $\mathrm{B}$ B target, predicts resistance to docetaxel in hormone-independent prostate cancer and nuclear factor- $\kappa \mathrm{B}$ inhibition by PS-1145 enhances docetaxel antitumor activity, Clin. Canc. Res. 12 (2006) 5578-5586.

[9] G. Liu, M. Qi, M.R. Hutchinson, G. Yang, E.M. Goldys, Recent advances in cytokine detection by immunosensing, Biosens. Bioelectron. 79 (2016) 810-821.

[10] S.M. Hanash, S.J. Pitteri, V.M. Faca, Mining the plasma proteome for cancer biomarkers, Nature 452 (2008) 571-579.

[11] R. Malhotra, V. Patel, J.P. Vaqué, J.S. Gutkind, J.F. Rusling, Ultrasensitive electrochemical immunosensor for oral cancer biomarker IL-6 using carbon nanotube forest electrodes and multilabel amplification, Anal. Chem. 82 (2010) 3118-3123.

[12] Y. Wang, J. Sun, Y. Hou, C. Zhang, D. Li, H. Li, M. Yang, C. Fan, B. Sun, RETRACTED: a SERS-based lateral flow assay biosensor for quantitative and ultrasensitive detection of interleukin-6 in unprocessed whole blood, Biosens. Bioelectron. 141 (2019) 111432.

[13] P. Chen, M.T. Chung, W. McHugh, R. Nidetz, Y. Li, J. Fu, T.T. Cornell, T.P. Shanley, K. Kurabayashi, Multiplex serum cytokine immunoassay using nanoplasmonic biosensor microarrays, ACS Nano 9 (2015) 4173-4181.

[14] A.T.E. Vilian, K. Giribabu, S.R. Choe, R. Muruganantham, H. Lee, C. Roh, Y.S. Huh, Y.-K. Han, A spick-and-span approach to the immobilization of horseradish peroxidase on Au nanospheres incorporated with a methionine/ graphene biomatrix for the determination of endocrine disruptor bisphenol A, Sensor. Actuator. B Chem. 251 (2017) 804-812.

[15] A. Tolga Çolak, T. Eren, M.L. Yola, E. Beşli, O. Şahin, N. Atar, 3D polyoxometalate-functionalized graphene quantum dots with mono-metallic and Bi-metallic nanoparticles for application in direct methanol fuel cells, J. Electrochem. Soc. 163 (2016) F1237-F1244.

[16] N.D. Quang, T.T. Hien, N.D. Chinh, D. Kim, C. Kim, D. Kim, Transport of photogenerated electrons and holes in $\mathrm{TiO} 2 / \mathrm{CdS} / \mathrm{CdSe}$ core-shell nanorod structure toward high performance photoelectrochemical cell electrode, Electrochim. Acta 295 (2019) 710-718.

[17] X. Ning, W. Zhen, Y. Wu, G. Lu, Inhibition of CdS photocorrosion by Al2O3 shell for highly stable photocatalytic overall water splitting under visible light irradiation, Appl. Catal. B Environ. 226 (2018) 373-383.

[18] J. Lee, S. Ham, D. Choi, D.-J. Jang, Facile fabrication of porous ZnS nanostructures with a controlled amount of S vacancies for enhanced photocatalytic performances, Nanoscale 10 (2018) 14254-14263.

[19] P. Zhang, X.W. Lou, Design of heterostructured hollow photocatalysts for solar-to-chemical energy conversion, Adv. Mater. 31 (2019) 1900281.

[20] P.-L. Wang, L.-H. Xie, E.A. Joseph, J.-R. Li, X.-O. Su, H.-C. Zhou, Metal-organic frameworks for food safety, Chem. Rev. 119 (2019) 10638-10690.

[21] Z. Tang, J. He, J. Chen, Y. Niu, Y. Zhao, Y. Zhang, C. Yu, A sensitive sandwichtype immunosensor for the detection of galectin-3 based on N-GNRs-FeMOFs@AuNPs nanocomposites and a novel AuPt-methylene blue nanorod, Biosens. Bioelectron. 101 (2018) 253-259.

[22] M.L. Yola, N. Atar, Amperometric galectin-3 immunosensor-based gold nanoparticle-functionalized graphitic carbon nitride nanosheets and core-shell Ti-MOF@COFs composites, Nanoscale 12 (2020) 19824-19832.

[23] G.-B. Hu, C.-Y. Xiong, W.-B. Liang, X.-S. Zeng, H.-L. Xu, Y. Yang, L.-Y. Yao, R. Yuan, D.-R. Xiao, Highly stable mesoporous luminescence-functionalized MOF with excellent electrochemiluminescence property for ultrasensitive immunosensor construction, ACS Appl. Mater. Interfaces 10 (2018) 15913-15919.

[24] B.Đ. Glišić, U. Rychlewska, M.I. Djuran, Reactions and structural characterization of gold(iii) complexes with amino acids, peptides and proteins, Dalton Trans. 41 (2012) 6887-6901.

[25] P. Zhang, B.Y. Guan, L. Yu, X.W. Lou, Facile synthesis of multi-shelled ZnS-CdS 
cages with enhanced photoelectrochemical performance for solar energy conversion, Inside Chem. 4 (2018) 162-173.

[26] X. Bai, Y. Zhang, W. Gao, D. Zhao, D. Yang, N. Jia, Hollow ZnS-CdS nanocage based photoelectrochemical sensor combined with molecularly imprinting technology for sensitive detection of oxytetracycline, Biosens. Bioelectron. 168 (2020) 112522.

[27] B. Jeong, R. Akter, O.H. Han, C.K. Rhee, M.A. Rahman, Increased electrocatalyzed performance through dendrimer-encapsulated gold nanoparticles and carbon nanotube-assisted multiple bienzymatic labels: highly sensitive electrochemical immunosensor for protein detection, Anal. Chem. 85 (2013) 1784-1791.

[28] M.L. Yola, N. Atar, Development of cardiac troponin-I biosensor based on boron nitride quantum dots including molecularly imprinted polymer, Biosens. Bioelectron. 126 (2019) 418-424.

[29] L. Wu, X. Lu, X. Fu, L. Wu, H. Liu, Gold nanoparticles dotted reduction graphene oxide nanocomposite based electrochemical aptasensor for selective, rapid, sensitive and congener-specific PCB77 detection, Sci. Rep. 7 (2017) 5191.

[30] J. Cravillon, R. Nayuk, S. Springer, A. Feldhoff, K. Huber, M. Wiebcke, Controlling zeolitic imidazolate framework nano- and microcrystal formation: insight into crystal growth by time-resolved in situ static light scattering, Chem. Mater. 23 (2011) 2130-2141.

[31] X. Chen, S. Shen, L. Guo, S.S. Mao, Semiconductor-based photocatalytic hydrogen generation, Chem. Rev. 110 (2010) 6503-6570.

[32] J. Low, J. Yu, M. Jaroniec, S. Wageh, A.A. Al-Ghamdi, Heterojunction photocatalysts, Adv. Mater. 29 (2017) 1601694.

[33] P. Bhanja, S.K. Das, K. Bhunia, D. Pradhan, T. Hayashi, Y. Hijikata, S. Irle, A. Bhaumik, A new porous polymer for highly efficient capacitive energy storage, ACS Sustain. Chem. Eng. 6 (2018) 202-209.

[34] A. Jorio, E.H.M. Ferreira, M.V.O. Moutinho, F. Stavale, C.A. Achete, R.B. Capaz, Measuring disorder in graphene with the G and D bands, Phys. Status Solidi (b) 247 (2010) 2980-2982.

[35] Y. Liu, D.Y. Kim, Ultraviolet and blue emitting graphene quantum dots synthesized from carbon nano-onions and their comparison for metal ion sensing, Chem. Commun. 51 (2015) 4176-4179.

[36] K. Bindumadhavan, P.-Y. Chang, R.-a. Doong, Silver nanoparticles embedded boron-doped reduced graphene oxide as anode material for high performance lithium ion battery, Electrochim. Acta 243 (2017) 282-290.

[37] A. Dutta Chowdhury, R.-a. Doong, Highly sensitive and selective detection of nanomolar ferric ions using dopamine functionalized graphene quantum dots, ACS Appl. Mater. Interfaces 8 (2016) 21002-21010.

[38] M. Wang, C. Fu, X. Liu, Z. Lin, N. Yang, S. Yu, Probing the mechanism of plasma protein adsorption on Au and Ag nanoparticles with FT-IR spectroscopy, Nanoscale 7 (2015) 15191-15196.

[39] J. Yu, X. Wang, Q. Kang, J. Li, D. Shen, L. Chen, One-pot synthesis of a quantum dot-based molecular imprinting nanosensor for highly selective and sensitive fluorescence detection of 4-nitrophenol in environmental waters, Environ. Sci.: Nano 4 (2017) 493-502.

[40] C. Sun, J.-h. Zhang, X.-f. Yuan, J.-n. Duan, S.-w. Deng, J.-m. Fan, J.-K. Chang, M.s. Zheng, Q.-f. Dong, ZIF-8-Based quasi-solid-state electrolyte for lithium batteries, ACS Appl. Mater. Interfaces 11 (2019) 46671-46677.

[41] H. Kaur, G.C. Mohanta, V. Gupta, D. Kukkar, S. Tyagi, Synthesis and characterization of ZIF-8 nanoparticles for controlled release of 6-mercaptopurine drug, J. Drug Deliv. Sci. Technol. 41 (2017) 106-112.

[42] W. Zhang, X. Jiang, Y. Zhao, A. Carné-Sánchez, V. Malgras, J. Kim, J.H. Kim, S. Wang, J. Liu, J.-S. Jiang, Y. Yamauchi, M. Hu, Hollow carbon nanobubbles: monocrystalline MOF nanobubbles and their pyrolysis, Chem. Sci. 8 (2017) 3538-3546.

[43] Z.-X. Cai, H. Yang, Y. Zhang, X.-P. Yan, Preparation, characterization and evaluation of water-soluble l-cysteine-capped-CdS nanoparticles as fluorescence probe for detection of $\mathrm{Hg}$ (II) in aqueous solution, Anal. Chim. Acta 559 (2006) 234-239.

[44] X. Yu, P. Wei, Y. Li, Enhanced sunlight photocatalytic performance of ZnO/ZnS binary heterostructure sheets, Mater. Lett. 240 (2019) 284-286.

[45] J. Zhang, W. Li, Y. Li, L. Zhong, C. Xu, Self-optimizing bifunctional CdS/Cu2S with coexistence of light-reduced $\mathrm{Cu} 0$ for highly efficient photocatalytic $\mathrm{H} 2$ generation under visible-light irradiation, Appl. Catal. B Environ. 217 (2017)
$30-36$.

[46] H.W. Yihe Jia, Long Xiang, Xiaoguang Liu, Wei Wei, Ma Ning, Dongbai Sun, Tunable emission properties of core-shell ZnCuInS-ZnS quantum dots with enhanced fluorescence intensity, J. Mater. Sci. Technol. 34 (2018) 942-948.

[47] X. Zhang, J. Peng, Y. Song, Y. Chen, F. Lu, W. Gao, Porous hollow carbon nanobubbles@ZnCdS multi-shelled dodecahedral cages with enhanced visible-light harvesting for ultrasensitive photoelectrochemical biosensors, Biosens. Bioelectron. 133 (2019) 125-132.

[48] Z. Mei, M. Zhang, J. Schneider, W. Wang, N. Zhang, Y. Su, B. Chen, S. Wang, A.L. Rogach, F. Pan, Hexagonal Zn1-xCdxS $(0.2 \leq \mathrm{x} \leq 1)$ solid solution photocatalysts for H2 generation from water, Catal. Sci. Technol. 7 (2017) 982-987.

[49] S. Sarma, S.C. Ray, Trigonal (1T) and hexagonal (2H) mixed phases MoS2 thin films, Appl. Surf. Sci. 474 (2019) 227-231.

[50] M.L. Yola, N. Atar, Z. Üstündağ, A.O. Solak, A novel voltammetric sensor based on p-aminothiophenol functionalized graphene oxide/gold nanoparticles for determining quercetin in the presence of ascorbic acid, J. Electroanal. Chem. 698 (2013) 9-16.

[51] J. Ju, W. Chen, In situ growth of surfactant-free gold nanoparticles on nitrogen-doped graphene quantum dots for electrochemical detection of hydrogen peroxide in biological environments, Anal. Chem. 87 (2015) 1903-1910.

[52] N. Elahi, M. Kamali, M.H. Baghersad, Recent biomedical applications of gold nanoparticles: a review, Talanta 184 (2018) 537-556.

[53] M.L. Yola, N. Atar, Functionalized graphene quantum dots with Bi-metallic nanoparticles composite: sensor application for simultaneous determination of ascorbic acid, dopamine, uric acid and tryptophan, J. Electrochem. Soc. 163 (2016) B718-B725.

[54] M. Tertis, P.I. Leva, D. Bogdan, M. Suciu, F. Graur, C. Cristea, Impedimetric aptasensor for the label-free and selective detection of Interleukin-6 for colorectal cancer screening, Biosens. Bioelectron. 137 (2019) 123-132.

[55] M. Tertiş, B. Ciui, M. Suciu, R. Săndulescu, C. Cristea, Label-free electrochemical aptasensor based on gold and polypyrrole nanoparticles for interleukin 6 detection, Electrochim. Acta 258 (2017) 1208-1218.

[56] C. Russell, A.C. Ward, V. Vezza, P. Hoskisson, D. Alcorn, D.P. Steenson, D.K. Corrigan, Development of a needle shaped microelectrode for electrochemical detection of the sepsis biomarker interleukin-6 (IL-6) in real time, Biosens. Bioelectron. 126 (2019) 806-814.

[57] J. Peng, L.-N. Feng, Z.-J. Ren, L.-P. Jiang, J.-J. Zhu, Synthesis of silver nanoparticle-hollow titanium phosphate sphere hybrid as a label for ultrasensitive electrochemical detection of human interleukin-6, Small 7 (2011) 2921-2928.

[58] C. Wang, N. Zhang, D. Wei, R. Feng, D. Fan, L. Hu, Q. Wei, H. Ju, Double electrochemiluminescence quenching effects of Fe304@PDA-CuXO towards selfenhanced Ru(bpy)32+ functionalized MOFs with hollow structure and it application to procalcitonin immunosensing, Biosens. Bioelectron. 142 (2019) 111521.

[59] D. Huang, H. Ying, D. Jiang, F. Liu, Y. Tian, C. Du, L. Zhang, X. Pu, Rapid and sensitive detection of interleukin-6 in serum via time-resolved lateral flow immunoassay, Anal. Biochem. 588 (2020) 113468.

[60] S. Giorgi-Coll, M.J. Marín, O. Sule, P.J. Hutchinson, K.L.H. Carpenter, Aptamermodified gold nanoparticles for rapid aggregation-based detection of inflammation: an optical assay for interleukin-6, Microchim. Acta 187 (2019) 13.

[61] C. Cao, R. Jin, H. Wei, Z. Liu, S. Ni, G.-J. Liu, H.A. Young, X. Chen, G. Liu, Adaptive in vivo device for theranostics of inflammation: real-time monitoring of interferon- $\gamma$ and aspirin, Acta Biomater. 101 (2020) 372-383.

[62] J. Xia, D. Lu, Y. Liu, M. Ran, J. Shang, L. Bi, X. Cao, Prediction of premature rupture of membranes via simultaneous detection of procalcitonin and interleukin-6 by a SERS-based immunochromatographic assay, New J. Chem. 44 (2020) 17099-17111.

[63] E.B. Aydın, Highly sensitive impedimetric immunosensor for determination of interleukin 6 as a cancer biomarker by using conjugated polymer containing epoxy side groups modified disposable ITO electrode, Talanta 215 (2020) 120909.

[64] https://www.thermofisher.com/elisa/product/IL-6-Human-ELISA-Kit/EH2IL6.

[65] https://www.raybiotech.com/human-il6-elisa-kit/. 